\section{Factores asociados con la seropositividad a Brucella canis en criaderos caninos de dos regiones de Antioquia, Colombia}

\author{
Factors associated with Brucella canis seropositivity \\ in kennels of two regions of Antioquia, Colombia
}

\author{
Fatores associados à soropositividade por Brucella \\ canis em cães reprodutores em duas regiões no \\ Estado de Antioquia, Colômbia
}

\author{
${ }^{1}$ Grupo de Investigación \\ VERICEL, Universidad \\ de Antioquia, Medellín, \\ Colombia. \\ Correspondencia \\ L. Castrillón-Salazar \\ Grupo de Investigación \\ VERICEL, Universidad de \\ Antioquia. \\ Carrera 75 n. 65-87, Bloque \\ 46, Oficina 202, Medellín, \\ Antioquia 050034, Colombia. \\ lalucasa7@gmail.com
}

\begin{abstract}
The objectives of this study were to determine Brucella canis seroprevalence in dogs and in humans living near kennels and to explore risk factors associated with seropositivity. Twenty kennels were included in a serological survey with RSAT-2ME, and samples were collected from 428 dogs and 91 humans. An interview was applied to determine risk factors, and the data were analyzed using logistic regression. Seroprevalence was $15 \%$ in dogs and $9 \%$ in humans. Factors associated with current canine seropositivity were: history of canine seropositivity, non-culling of seropositive dogs, history of abortion, poor hygiene and personal protection during reproductive service, and unsafe procedures during care for abortions. Protective factors included: rural location of kennels, ease of cleaning kennels, pre-mating RSAT-2ME, and safe procedures during care for delivery. Factors associated with seropositive status in humans were: kennels located in Valle de Aburrá and urban location.
\end{abstract}

Seroepidemiologic Studies; Brucellosis; Zoonoses
Laura Castrillón-Salazar 1

Carlos Andrés Giraldo-Echeverri 1

Miryan Margot Sánchez-Jiménez 1

Martha Olivera-Angel 1

\section{Resumen}

El objetivo fue determinar la seroprevalencia a Brucella canis en perros y humanos convivientes en criaderos caninos y explorar los factores de riesgo asociados a la seropositividad. Se tomaron 20 criaderos, en los cuales se realizó diagnóstico serológico por PARP-2ME de 428 caninos y 91 humanos. Se aplicó una encuesta para determinar los factores de riesgo y se analizaron los datos mediante regresión logística. Se determinó una seroprevalencia de $15 \%$ en caninos y $9 \%$ en humanos convivientes. Se determinaron como factores asociados a la seropositividad canina el historial de seropositividad canina, conservar los caninos seropositivos, historial de aborto, higiene y protección del operario deficientes $d u$ rante el servicio reproductivo, y procedimiento inseguro durante la atención de abortos. Como factores protectores se establecieron la ubicación rural de los criaderos, facilidad de aseo de los caniles, PARP-2ME premonta, y procedimiento seguro durante la atención de partos. En humanos se determinaron factores asociados: criaderos ubicados en el Valle Aburrá y de tipo urbano.

Estudios Seroepidemiológicos; Brucelosis; Zoonosis 


\section{Introducción}

Brucella canis es una bacteria del género Brucella spp., igual que B. melitensis, B. abortus y B. suis, principales agentes etiológicos de la brucelosis humana 1 . Esta enfermedad es considerada la zoonosis bacteriana más prevalente a nivel mundial, provocando más de 500.000 casos nuevos anuales e implicando una alta morbilidad en la población expuesta1,2. Desde su aislamiento en 1966, B. canis ha logrado una distribución mundial, y es considerada el principal agente causal de abortos y esterilidad en caninos 3,4. Las rutas de transmisión en caninos son: venérea, oronasal y conjuntival; el principal síntoma en las hembras es el aborto en el último tercio de la gestación, y en los machos, epididimitis, prostatitis, además de infertilidad en ambos 5,6. Existen otros signos clínicos relacionados, como uveítis, opacidad corneal y trastornos articulares, principalmente discoespondilitis, y sintomatología inespecífica como letargia, pérdida de peso, intolerancia al ejercicio, linfadenitis y cambios comportamentales 6 . Con respecto a la población canina en Medellín (Colombia), entre 2005 y 2008, se encontró una frecuencia del $11 \%$ de seropositivos a partir de las muestras remitidas a la Universidad de Antioquia 7, y en el 2009, se reportó un 6,8\% de seropositivos en el albergue canino local 8.

La convivencia de personas con perros infectados, y la manipulación de fluidos reproductivos, implica un riesgo zoonótico alto 9 , asimismo, la seroprevalencia puede alcanzar hasta el $68 \%$ en humanos en permanente contacto con perros ${ }^{10}$. A nivel mundial, se han reportado varios casos de humanos positivos con aislamiento de B. canis $^{9,11,12}$, los cuales han sido principalmente personas convivientes con caninos infectados, como criadores y poseedores de mascotas, profesionales del área de la salud animal y en contacto con material biológico, adicionalmente, personas inmunocomprometidas como niños y enfermos de VIH 9,11,13. En Latinoamérica, en los últimos años se han reportado varios casos humanos 9,14 provocados por $B$. canis, coincidiendo, además, con altos porcentajes de seroprevalencia canina en diferentes ciudades 15,16,17,18. En Colombia, se han encontrado criadores asintomáticos seropositivos y se logró el aislamiento de la bacteria en uno de ellos 19

Las infecciones declaradas por la Organización Internacional de Epizootias (OIE) como enfermedades zoonóticas ameritan medidas específicas de prevención, diagnóstico y control. Para ello, se evalúan diferentes aspectos de la población, que orientan la identificación de riesgo de infección 20, y este riesgo, por lo general, está condicionado a la exposición. Los factores de riesgo son características, condiciones o circunstancias, que condicionan a que exista una mayor probabilidad de que ocurra un evento 21 . Según Al-Shamahy et al. 22, los factores de riesgo para el contagio con brucelosis están relacionados con prácticas culturales y factores ocupacionales.

La transmisión de $B$. canis a humanos se da principalmente por contacto directo con descargas vaginales, productos de abortos, fluidos y orina de machos y hembras infectados. En los criaderos caninos, estos factores de exposición ocurren fácilmente 9 . Como sintomatología en humanos, se conocen casos con fiebre recurrente, fatiga, dolor de cabeza, problemas osteoarticulares como discoespondilitis, osteítis, artralgias, dada la capacidad de infectar los osteoblastos humanos, e inducir respuesta de citoquinas en estas células 23 , linfadenopatías y malestar general son otros síntomas asociados a la brucelosis en humanos 24 . La brucelosis se considera una enfermedad incapacitante por los síntomas dolorosos que presenta de forma recurrente, y en las presentaciones nerviosa o cardiovascular, aunque menos frecuentes, se considera mortal 1,2.

Teniendo en cuenta la alta frecuencia de seropositividad reportada en Medellín entre 2005 y 2008 7, y el desconocimiento de la situación actual de la enfermedad a nivel de criaderos, se buscó determinar la seroprevalencia en caninos y humanos, y los factores asociados a ella; a partir de información sobre prácticas productivas, reproductivas y sanitarias realizadas en el criadero, y muestras sanguíneas en ambas poblaciones.

\section{Materiales y métodos}

El estudio corresponde al área de la salud pública, enfocado a la epidemiología veterinaria, con un análisis de tipo descriptivo y de corte transversal. Este estudio cumple con los lineamientos éticos establecidos para la experimentación animal, toma y manipulación de muestras caninas y humanas.

\section{Selección de la muestra}

Durante 2010 y 2011 se convocaron a 50 propietarios de criaderos caninos en el Valle de Aburrá y de Oriente cercano a Antioquia.

La región Valle de Aburrá se encuentra a $1.500 \mathrm{msnm}$, con una temperatura ambiental de $23,5^{\circ} \mathrm{C}\left(15\right.$ a $\left.32^{\circ} \mathrm{C}\right)$, humedad relativa de $68 \%$. La región Oriente cercana a Antioquia se encuentra a $2.100 \mathrm{msnm}$, con una temperatura de $17^{\circ} \mathrm{C}$, y humedad relativa de $80 \%$ (portal de la ciudad de Rionegro. Datos del municipio de Rionegro. http://www.rionegro.gov.co/datos-del-Munici 
pio-de-Rionegro, accedido el 04/Mar/2013); (El Carmen de Viboral. Ecología. http://www.elcar mendeviboral-antioquia.gov.co/nuestromunici pio.shtml?apc $=\mathrm{mIxx}-1-\& \mathrm{~m}=\mathrm{f} \#$ ecologia, accedido el 04/Mar/2013); (El Retiro moderno, cívico y pujante. Ecología. http://www.elretiro-antioquia. gov.co/nuestromunicipio.shtml?apc $=$ mIxx-1 $\& \mathrm{~m}=\mathrm{f} \#$ ecologia, accedido el 04/Mar/2013); (portal de la ciudad de Medellín. Datos generales de la ciudad. http://www.medellin.gov.co/irj/por tal/visitantes?NavigationTarget=navurl://ff556e d54f8f4fb94e0c28e0bb15d9c8, accedido el 04/ Mar/2013).

Como criterios de selección se consideraron: mínimo diez caninos en el criadero, autorizar con un consentimiento informado la toma de muestras sanguíneas (humanos y caninos), la realización de una visita a las instalaciones, y de una encuesta sobre manejo del criadero. De los criaderos inscritos se seleccionaron a conveniencia diez para Valle de Aburrá y diez para Oriente cercano a Antioquia. La restricción a diez criaderos por región dependió de la disponibilidad de recursos. Los criterios de exclusión de los criaderos fueron: no aceptar la toma de muestras de los humanos y/o no cumplir con el número mínimo de caninos. Se incluyeron criaderos de diferentes puntos cardinales y niveles socioeconómicos.

Se definió como "núcleo" un criadero conformado por los caninos y las personas convivientes con estos. Los núcleos tenían de diez a 80 caninos, de los cuales se muestrearon entre 6-76 (Tabla 1), para un total de 428 (Valle de Aburrá = 220, Oriente cercano de Antioquia = 208). No se realizó estimación de la muestra, pues el objetivo era tomar muestras de todos los caninos de cada criadero. Se excluyeron los cachorros menores de un mes, las hembras en el último tercio de la gestación, y los caninos con tratamiento antibiótico en el último mes. Se tomaron 91 muestras de humanos de estos núcleos (Valle de Aburrá = 52, Oriente cercano de Antioquia = 39). Se excluyeron los niños menores de tres años de edad y personas que no aceptaran voluntariamente donar la muestra sanguínea. Aunque no se excluyó a quienes hubiesen recibido tratamiento antibiótico durante el último mes, si se consignó esta información por cada individuo.

\section{Encuestas para factores asociados}

En cada núcleo se realizó una encuesta que incluía: proyecto (Valle de Aburrá u Oriente cercano de Antioquia), ubicación del criadero (rural o urbano), el número de personas convivientes, número de caninos, material de construcción del criadero, prácticas de aseo y desinfección, prácticas reproductivas, tipo de servicio repro-
Tabla 1

Resultados positivos para la prueba de aglutinación rápida en placa con $2 \beta$-mercaptoetanol (PARP-2ME) en caninos y humanos.

\begin{tabular}{|c|c|c|c|c|}
\hline \multirow[t]{2}{*}{ Núcleo } & \multicolumn{2}{|c|}{ Caninos } & \multicolumn{2}{|c|}{ Humanos } \\
\hline & $\mathbf{n}$ & Seropositivos & n & Seropositivos \\
\hline 1 & 10 & 7 & 21 & 4 \\
\hline 2 * & 12 & 4 & - & - \\
\hline 3 & 20 & 0 & 5 & 0 \\
\hline 4 & 14 & 0 & 4 & 2 \\
\hline 5 & 14 & 0 & 3 & 0 \\
\hline 6 & 76 & 30 & 2 & 1 \\
\hline 7 & 14 & 4 & 5 & 0 \\
\hline 8 & 15 & 6 & 4 & 1 \\
\hline 9 & 35 & 6 & 4 & 1 \\
\hline 10 & 10 & 4 & 4 & 0 \\
\hline 11 & 14 & 0 & 5 & 0 \\
\hline 12 & 6 & 0 & 2 & 0 \\
\hline 13 & 24 & 0 & 1 & 0 \\
\hline 14 & 28 & 0 & 3 & 0 \\
\hline 15 & 10 & 0 & 7 & 0 \\
\hline 16 & 29 & 0 & 3 & 0 \\
\hline 17 & 50 & 0 & 6 & 0 \\
\hline 18 & 9 & 0 & 3 & 0 \\
\hline 19 & 23 & 0 & 6 & 0 \\
\hline 20 & 15 & 3 & 3 & 0 \\
\hline Total [n (\%)] & $428(100,0)$ & $64(14,9)$ & $91(100,0)$ & $9(9,0)$ \\
\hline
\end{tabular}

* Los propietarios de este criadero no accedieron a la toma de la muestra.

ductivo, atención ginecológica y obstétrica, así como atención neonatal (Tabla 2). A cada canino se le recopiló una historia, seguido de un examen clínico orientado a signos compatibles con brucelosis canina.

\section{Toma de muestras sanguíneas}

Las muestras caninas fueron tomadas por médicos veterinarios, las humanas por bacteriólogos. Tanto en humanos como en caninos, se tomaron $5 \mathrm{~mL}$ de sangre en tubos secos al vacío (Vacutainer, Becton, Dickinson and Company, New Jersey, Estados Unidos). Esta se transportó refrigerada al laboratorio, y se obtuvo el suero por centrifugación a 3000rpm durante cinco minutos.

Prueba de aglutinación rápida en placa con 2 $\beta$-mercaptoetanol (PARP-2ME)

Esta prueba serológica es el test sugerido por Carmichael \& Joubert 20. En humanos la prueba de elección es el ELISA indirecto, sin embargo, el PARP-2ME se considera una prueba útil 
Tabla 2

Variables evaluadas para factores asociados a Brucella canis y sus categorías, para caninos y humanos.

\begin{tabular}{|c|c|}
\hline Variable & Categorías * \\
\hline \multirow[t]{2}{*}{ Proyecto } & 0: Oriente de Antioquia \\
\hline & 1: Valle de Aburrá \\
\hline \multirow[t]{2}{*}{ Tipo de criadero } & 0: Rural \\
\hline & 1: Urbano \\
\hline \multirow[t]{2}{*}{ Delimitación entre el criadero y la vivienda } & 0: Sí \\
\hline & 1: No \\
\hline \multirow{2}{*}{$\begin{array}{l}\text { Facilidad de aseo (de acuerdo con el material : paredes, } \\
\text { suelos y techo) }\end{array}$} & 0: Fácil \\
\hline & \\
\hline \multirow[t]{2}{*}{ Disposición final de las excretas } & 0: Desagüe/Sifón \\
\hline & 1: Recolección \\
\hline \multirow[t]{2}{*}{ Tipo de servicio reproductivo } & 0: Inseminación artificial y monta natural \\
\hline & 1: Monta natural \\
\hline \multirow[t]{2}{*}{ Prueba PARP-2ME premonta } & 0: Sí \\
\hline & 1: No \\
\hline \multirow[t]{2}{*}{ Servicios reproductivos con caninos externos al criadero } & $0:$ No \\
\hline & 1: Sí \\
\hline \multirow[t]{3}{*}{ Higiene del técnico durante el servicio reproductivo } & 0: Buena \\
\hline & 1: Deficiente \\
\hline & 2: No aplica \\
\hline \multirow[t]{3}{*}{ Protección personal del técnico durante el servicio reproductivo } & 0: Buena \\
\hline & 1: Deficiente \\
\hline & 2: No aplica \\
\hline \multirow[t]{2}{*}{ Historial de seropositividad canina } & o: No \\
\hline & 1: Sí \\
\hline \multirow[t]{2}{*}{ Procedimiento con caninos seropositivos } & 0: Descarte \\
\hline & 1: Conservación \\
\hline \multirow[t]{3}{*}{ Procedimiento durante un parto } & 0: Seguro \\
\hline & 1: Inseguro \\
\hline & 2: No aplica \\
\hline \multirow[t]{2}{*}{ Historial de abortos en el criadero } & O: No \\
\hline & 1: Sí \\
\hline \multirow[t]{3}{*}{ Procedimiento durante un aborto } & 0: Seguro \\
\hline & 1: Inseguro \\
\hline & 2: No aplica \\
\hline \multirow[t]{2}{*}{ Disposición de material biológico } & 0: Seguro \\
\hline & 1: Inseguro \\
\hline \multirow[t]{2}{*}{ Disposición de material cortopunzante en un recipiente seguro } & 0: Sí \\
\hline & 1: No \\
\hline \multirow[t]{2}{*}{ Convivencia de humanos con caninos seropositivos } & 0: No \\
\hline & 1: Sí \\
\hline \multirow[t]{2}{*}{ Convivencia de humanos con caninos con hemocultivo positivo } & 0: No \\
\hline & 1: Sí \\
\hline
\end{tabular}

* Para la inclusión de los datos en el programa estadístico, se asignó (0) a la categoría de la variable que se considera óptima, y (1) a la categoría que se considera implica riesgo.

como tamizaje para diagnosticar presencia de anticuerpos contra $B$. canis, por ser elaborado con cepa M- de B. canis ${ }^{9}$. Para su realización, tanto en caninos como en humanos, se mezcla- ron $25 \mu \mathrm{L}$ del suero, $25 \mu \mathrm{L}$ de 2 - $\beta$-mercaptoetanol $(0,2 \%$, SIGMA $®$, M6250) durante un minuto, luego se adicionaron $50 \mu \mathrm{L}$ de antígeno B. canis cepa M-. Después de dos minutos de observación a 
contraluz en un aglutinoscopio se determinaron como positivas aquellas que presentaron aglutinación fina, similar al control positivo 7,20. El total de sueros caninos fueron procesados por una investigadora con tres años de experiencia en lectura de resultados serológicos.

\section{Análisis estadístico}

Para el establecimiento de los factores asociados a $B$. canis en caninos, se realizó un análisis descriptivo de las variables independientes por criadero (Tabla 2) y se asoció cada una con la variable dependiente: resultado serológico canino nominal. Las asociaciones con la variable dependiente, y la determinación de la razón de odds (OR), fueron procesadas mediante los programas SPSS versión 18 (SPSS Inc., Chicago, Estados Unidos) para las variables dicotómicas y las variables de más de dos categorías fueron analizadas de la misma manera, no obstante, para establecer la categoría que implicó riesgo o protección se analizaron mediante tablas 2x2 con el programa Epidat versión 3.1 (Xunta de Galicia, España; http:// dxsp.sergas.es/default.asp). Se realizó un análisis de regresión logística bivariada. Las variables que por el estadístico de Hosmer-Lemeshow mostraron un $\mathrm{p}<0,25$, con OR mayor a 1,0 e intervalo de confianza de 95\% (IC95\%), se determinaron como factores asociados; y las variables con un $\mathrm{p}<0,25$, OR menor a 1,0 con IC95\%, se determinaron como factores de protección. Las variables con un $\mathrm{p}<0,25$ por análisis bivariado (Tabla 3 ), se seleccionaron para incluirse en un modelo de regresión logística multivariado, en el cual se evaluó la interacción de estas variables en conjunto con la seroprevalencia nominal, ya que se pueden evidenciar asociaciones más fuertes.

En humanos, para determinar los factores asociados a la seropositividad a B. canis, se aplicó estadística descriptiva a las variables independientes descritas (Tabla 2), estas se asociaron con la variable dependiente: resultado serológico humano nominal, usando los mismos análisis y programas empleados en caninos.

Análisis bivariado de los factores asociados para la seropositividad a Brucella canis en caninos.

\begin{tabular}{|c|c|c|c|c|c|}
\hline \multirow[t]{2}{*}{ Variables independientes } & \multirow[t]{2}{*}{ Valor de $p$} & \multirow[t]{2}{*}{ OR } & \multicolumn{2}{|c|}{ IC95\% para OR } & \multirow{2}{*}{$\begin{array}{l}\text { R cuadrado de } \\
\text { Nagelkerke }\end{array}$} \\
\hline & & & Inferior & Superior & \\
\hline Proyecto & 0,000 & 26,216 & 8,076 & 85,098 & 0,265 \\
\hline Tipo de criadero & 0,000 & 1,374 & 1,271 & 1,486 & 0,319 \\
\hline Delimitación entre el criadero y la vivienda & 0,450 & 0,791 & 0,431 & 1,452 & 0,002 \\
\hline Disposición final de las excretas & 0,470 & 1,293 & 0,644 & 2,594 & 0,002 \\
\hline Facilidad de aseo & 0,060 & 2,211 & 1,262 & 3,875 & 0,033 \\
\hline Tipo de servicio reproductivo & 0,118 & 0,494 & 0,204 & 1,196 & 0,012 \\
\hline Prueba PARP-2ME premonta & 0,004 & 3,071 & 1,417 & 6,657 & 0,041 \\
\hline $\begin{array}{l}\text { Servicios reproductivos con caninos externos al } \\
\text { criadero }\end{array}$ & 0,490 & 0,827 & 0,482 & 1,419 & 0,002 \\
\hline Higiene del técnico durante el servicio reproductivo & 0,000 & 12,609 & 6,315 & 25,177 & 0,273 \\
\hline $\begin{array}{l}\text { Protección personal del técnico durante el servicio } \\
\text { reproductivo }\end{array}$ & 0,000 & 3,118 & 1,792 & 5,425 & 0,065 \\
\hline Historial de seropositividad canina & 0,000 & 7,620 & 3,656 & 15,883 & 0,161 \\
\hline Procedimiento con los caninos seropositivos & 0,000 & 3,571 & 1,767 & 7,219 & 0,079 \\
\hline Procedimiento durante un parto & 0,001 & 0,253 & 0,108 & 0,591 & 0,059 \\
\hline Historial de abortos en el criadero & 0,000 & 13,144 & 4,679 & 36,923 & 0,176 \\
\hline Procedimiento durante un aborto & 0,768 & 1,093 & 0,604 & 1,980 & 0,000 \\
\hline Disposición de material biológico & 0,181 & 2,062 & 0,715 & 5,953 & 0,009 \\
\hline $\begin{array}{l}\text { Disposición de material cortopunzante en un recipiente } \\
\text { seguro }\end{array}$ & 0,106 & 1,588 & 0,906 & 2,785 & 0,01 \\
\hline
\end{tabular}

IC95\%: intervalo de confianza de 95\%; OR: razón de odds. 


\section{Resultados}

Resultados de PARP-2ME en caninos y humanos

En ocho de los 20 criaderos se encontraron caninos seropositivos a B. canis. Uno de los criaderos positivos no permitió la toma de muestras humanas. De los siete criaderos positivos restantes, al menos en cuatro, una persona del núcleo fue positiva, y en 14 criaderos no se encontraron personas positivas. Los criaderos 1 a 10 se encuentran ubicados en Valle de Aburrá allí la seroprevalencia canina fue de $27,7 \%(61 / 220$ caninos); y del criadero 11 al 20, se encuentran ubicados en Oriente cercano a Antioquia, allí la seroprevalencia fue de un 1,4\% (3/208 caninos). Las nueve personas seropositivas se encontraron todas en Valle de Aburrá, obteniéndose así un $17,3 \%$ de seropositividad humana para esta región (9/52) y $0 \%$ para Oriente cercano a Antioquia.

En uno de los criaderos seronegativos para caninos, se encontraron dos personas del núcleo seropositivas. En la Tabla 1 se consignan los resultados de humanos y caninos por criadero.

\section{Factores asociados con B. canis en caninos}

Se establecieron como factores asociados las variables: "proyecto", con las categoría criadero en la región Valle de Aburrá ( $\mathrm{p}=0,000$, y OR $=26,21)$, "historial de abortos" ( $p=0,000$, y OR = 13,14), "higiene del técnico durante el servicio reproductivo" (deficiente) ( $p=0,000$, y $\mathrm{OR}=12,06)$, "historial de seropositividad canina" $(p=0,000, y \mathrm{OR}=7,62)$. Otros factores con menor valor en su OR son: "tipo de criadero" (urbano), "procedimiento con caninos seropositivos" (conservarlos), "facilidad de aseo" (difícil) y "prueba PARP-2ME premonta" (no). Asimismo, se halló como factor protector: "procedimiento al parto" (seguro). En la Tabla 3 se muestran las variables incluidas, los factores asociados y de protección, hallados por análisis bivariado.

En la Tabla 4 se muestran resultados del modelo de regresión logístico multivariado, de ellos se seleccionó el modelo 4o, en el cual se pudo observar con el 95\% de confianza, la significancia de las variables "higiene del técnico durante el servicio reproductivo" e "historial de seropositividad canina" como factores asociados con la seropositividad canina, (coeficientes B: 4,164 y 1,144 respectivamente), $p=0,000$ y 0,006 respectivamente; OR > 1, con IC95\%, sin contener el 1,0 .

Las variables "proyecto" (Oriente cercano a Antioquia) y "disposición de material biológico" (seguro) con coeficientes B $=-2,187$ y $-3,477$ respectivamente, con IC95\%, sin contener al 1,0, constituyen factores protectores.

\section{Factores asociados con B. canis en humanos}

Como se puede observar en la tabla 5, por análisis bivariado los criaderos ubicados en la región Valle de Aburrá ("proyecto") y los criaderos de tipo urbano, representan riesgo para la seropositividad humana ( $p=0,000$; OR = 1,20 y 1,19), con un IC95\%. El "procedimiento durante un parto" (seguro), representa un factor protector para la seronegatividad humana, $\mathrm{p}=0,000 ; \mathrm{OR}=0,0$.

\section{Asociación de sintomatología hallada en caninos con seropositividad a B. canis}

Los resultados en la Tabla 3 son factores analizados a nivel de criadero, tomando estos como núcleos y asociando las variables presentes en cada criadero con la cantidad de caninos seropositivos. Además, analizamos el riesgo de seropositividad para el total de perras $(n=305)$ que han presentado al menos un aborto, y presentan seis veces más probabilidad de ser seropositivas a $B$. canis $(\mathrm{p}<005, \mathrm{OR}=6$, IC95\%).

\section{Discusión}

Existen pocos estudios de seropositividad a $B$. canis en criaderos caninos en el mundo, además, todos fueron reportados tras un brote o caso clínico, por lo tanto, presentan muestras pequeñas (n < 40) y altas prevalencias (Hungría, 23\% 17; Canadá, $60,6 \% 25)$. En nuestro estudio encontramos una seropositividad canina igual a $15 \%$ en criaderos de ambas regiones, en los cuales hasta el momento del análisis no se había reportado la problemática.

Si comparamos estos resultados de seropositividad, con reportes en Medellín u otras ciudades, esta supera la frecuencia del $8,9 \%$ reportada por Giraldo et al. 7 en el 2009 para caninos de criaderos en el área metropolitana, aunque en nuestro estudio la muestra fue seleccionada a conveniencia. Si evaluamos la frecuencia en Valle de Aburrá (27,7\%), encontramos que supera la frecuencia de $17,2 \%$ reportada por Jara et al. 26 , en 2005, en esta misma región. De igual manera, comparados con estudios de seropositividad en centros urbanos, donde no se discrimina la procedencia de los caninos, la seroprevalencia en Valle de Aburrá es mayor a la reportada en Bogotá (20\%) entre 2001 y 2002 27; y a nivel de Latinoamérica, se han reportado seroprevalencias de $15,6 \%$ en el distrito del Callao, Perú $28 ; 7,3 \%$ en 
Modelo de regresión logística multivariado para los factores asociados a la seropositividad a Brucella canis.

\begin{tabular}{|c|c|c|c|c|c|c|}
\hline \multirow{2}{*}{$\begin{array}{l}\text { Modelo regresión } \\
\text { logística }\end{array}$} & \multirow[t]{2}{*}{ Variable } & \multirow[t]{2}{*}{$\beta$} & \multirow[t]{2}{*}{ Valor de p } & \multirow[t]{2}{*}{ OR } & \multicolumn{2}{|c|}{ IC95\% para OR } \\
\hline & & & & & Inferior & Superior \\
\hline \multirow[t]{4}{*}{ 4으 } & Proyecto & $-2,187$ & 0,000 & 0,112 & 0,046 & 0,274 \\
\hline & $\begin{array}{l}\text { Higiene del técnico durante el servicio } \\
\text { reproductivo }\end{array}$ & 4,164 & 0,000 & 64,322 & 17,099 & 241,965 \\
\hline & Historial de seropositividad & 1,144 & 0,006 & 3,139 & 1,390 & 7,087 \\
\hline & Disposición de material biológico & $-3,477$ & 0,000 & 0,031 & 0,009 & 0,104 \\
\hline
\end{tabular}

IC95\%: intervalo de confianza de 95\%; OR: razón de odds.

Tabla 5

Análisis bivariado de los factores asociados con la seropositividad a Brucella canis en humanos relacionados con criaderos caninos.

\begin{tabular}{|c|c|c|c|c|c|}
\hline \multirow[t]{2}{*}{ Variables independientes } & \multirow[t]{2}{*}{ Valor de $p$} & \multirow[t]{2}{*}{ OR } & \multicolumn{2}{|c|}{ IC95\% para OR } & \multirow{2}{*}{$\begin{array}{l}\text { R cuadrado de } \\
\text { Nagelkerke }\end{array}$} \\
\hline & & & Inferior & Superior & \\
\hline Proyecto & 0,006 & 1,209 & 1,068 & 1,369 & 0,236 \\
\hline Tipo de criadero & 0,011 & 1,196 & 1,064 & 1,344 & 0,213 \\
\hline Delimitación entre el criadero y la vivienda & 0,808 & 0,842 & 0,210 & 3,369 & 0,001 \\
\hline Disposición final de las excretas & 0,805 & 1,190 & 0,298 & 4,752 & 0,001 \\
\hline Facilidad de aseo & 0,847 & 1,179 & 0,223 & 6,221 & 0,001 \\
\hline Tipo de servicio reproductivo & 0,458 & 0,444 & 0,052 & 3,791 & 0,015 \\
\hline Prueba PARP-2ME premonta & 0,949 & 1,056 & 0,202 & 5,513 & 0,000 \\
\hline $\begin{array}{l}\text { Servicios reproductivos con caninos externos al } \\
\text { criadero }\end{array}$ & 0,132 & 0,195 & 0,023 & 1,636 & 0,073 \\
\hline Higiene del técnico durante el servicio reproductivo & 0,561 & 1,324 & 0,514 & 3,410 & 0,008 \\
\hline $\begin{array}{l}\text { Protección personal del técnico durante el servicio } \\
\text { reproductivo }\end{array}$ & 0,375 & 0,489 & 0,100 & 2,378 & 0,026 \\
\hline Historial de seropositividad canina & 0,601 & 1,447 & 0,362 & 5,780 & 0,006 \\
\hline Procedimiento con los caninos seropositivos & 0,693 & 1,357 & 0,298 & 6,176 & 0,004 \\
\hline Procedimiento durante un parto * & 0,998 & 0,000 & 0,000 & & 0,131 \\
\hline Historial de abortos en el criadero & 0,093 & 4,056 & 0,794 & 20,691 & 0,076 \\
\hline Procedimiento durante un aborto & 0,092 & 0,431 & 0,162 & 1,147 & 0,073 \\
\hline Disposición de material biológico & 0,211 & 0,327 & 0,057 & 1,884 & 0,031 \\
\hline $\begin{array}{l}\text { Disposición de material cortopunzante en un } \\
\text { recipiente seguro }\end{array}$ & 0,183 & 2,686 & 0,628 & 11,488 & 0,043 \\
\hline Convivencia con seropositivos & 0,072 & 4,472 & 0,875 & 22,845 & 0,088 \\
\hline
\end{tabular}

IC95\%: intervalo de confianza de 95\%; OR: razón de odds.

* Debido a la ausencia de humanos seropositivos en núcleos con la condición procedimiento durante un parto, los programas epidemiológicos empleados no pueden establecer un límite superior de intervalo de confianza, sin embrago, por la pruebas estadísticas empleadas (Hosmer-Lemeshow: valor de p y la razón de prevalencias: OR) se puede hacer esta inferencia.

Buenos Aires, Argentina 29 y 14,2\% en Brasil 15, todos realizados en áreas urbanas.

El análisis de factores asociados evidenció que los criaderos ubicados en Valle de Aburrá
$(\mathrm{OR}=26,16)$ constituyen un factor asociado con la seropositividad canina por análisis bivariado. Esta variable se relaciona estrechamente con la condición urbana de los estudios mencionados 
anteriormente, como lo indican otros autores 27,28,30; haciendo referencia a la alta interacción entre caninos, debido a la menor disponibilidad de espacio, entorno en el cual los perros infectados, comparten espacios con otros sanos para jugar, defecar o miccionar y se facilita el riesgo de transmisión 28,30. Esta condición se ve reforzada por diferentes variables establecidas como factores asociados por análisis bivariado, como son: dificultad de aseo de los caniles, servicio reproductivo con caninos de otros criaderos, historial de abortos y de seropositividad; las cuales fueron más frecuentes en los criaderos de esta región. Además, las características de las instalaciones son mejores en Oriente cercano a Antioquia, debido a diferencias socioeconómicas, que permiten una mayor inversión en los criaderos caninos.

Igualmente, en el modelo de regresión logística multivariado (Tabla 4), la ubicación de los criaderos en Oriente cercano a Antioquia constituye un factor protector para la seronegatividad canina ( $p=0,000$; $O R=0,112$ ). Dicho hallazgo se relaciona con la posibilidad de los criadores para acceder a un mayor espacio donde alojar a los caninos, evitando así el hacinamiento. Además, las condiciones de cría y manejo de los criaderos en el oriente cercano de Antioquia son más tecnificadas, si se evalúan desde lo sugerido por la normativa internacional para criaderos caninos 31 , y por diversos autores 28,32; y poseen mayor nivel de organización administrativa, si se compara con los criaderos de Valle de Aburrá, que no cumplen especificaciones técnicas.

Los criaderos con historial de aborto tienen 13 veces mayor probabilidad de seropositividad que los criaderos sin esta característica (Tabla 3), lo cual concuerda con estudios anteriores, donde relacionan la seropositividad con antecedentes reproductivos 28 . La eliminación de la bacteria durante y posterior al aborto es muy alta $(>1010$ bacterias/mL de fluido) 4,16 , y puede persistir por meses e incluso años, de forma intermitente 6,33; corroborando que es esta la principal ruta de eliminación y transmisión de la hembras 17. Borie et al. 34 y Álvarez \& Casco 33 comprobaron que un canino tras 4-8 semanas de infección alcanza una eliminación de 103-106 bacterias/ $\mathrm{mL}$ de orina o semen y $10^{10}$ por descargas vaginales posteriores al aborto o parto. A esto debemos sumar que la dosis infectiva vía oral es de $10^{6}$ bacterias y, de 103-4 bacterias, vía mucosa conjuntival 28 ; lo cual quiere decir, que un criadero que no tome medidas sanitarias suficientes para eliminar la infección del criadero, mantendrá las bacterias vivas y circulantes durante un amplio periodo de tiempo, con riesgo de infección.

La poca desinfección, e inadecuada eliminación de fetos y fluidos placentarios posteriores al parto y al aborto, se asocian con la seropositividad del criadero, evidenciando el desconocimiento sobre la facilidad de transmisión de $B$. canis por esta fuente a caninos y humanos 28 . Stanchi et al. ${ }^{18}$ y Hollet 6 describieron como factores asociados la ausencia de depósitos especiales para material biológico contaminado y la necesidad de indumentaria apta para la protección personal; ya que la manipulación sanitaria o quirúrgica de utensilios, cuando entran en contacto con animales sanos, son una vía de infección. El procedimiento seguro ante los partos y la disposición segura de material biológico se establecieron como factores protectores para la seronegatividad canina por análisis bivariado y multivariado respectivamente $(\mathrm{OR}=0,253 \mathrm{y}$ 0,031 ) (Tablas 3 y 4), indicando la importancia de tomar medidas de protección personal, separación de la perra en proceso de parto, y limpieza y desinfección del área de parto posterior a este. La exposición de los caninos sanos a productos de partos y abortos se ha reportado como una forma fácil de transmisión de $B$. canis 28,35 .

La dificultad para asear los caniles ( $\mathrm{OR}=2,2$, Tabla 3) se relaciona estrechamente con los factores asociados y de protección anteriores. El género Brucella se ve favorecido por ambientes húmedos, ricos en materia orgánica. La bacteria puede sobrevivir en heces húmedas, orina, polvo, agua, suelo, material biológico congelado por periodos de tiempo que varían, según el material, entre dos y 22 semanas 28,36,37; también puede ser aerosolizada en animales o esparcidas sobre fómites ${ }^{6}$. Si se tiene en cuenta la carga bacteriana contenida en partos y abortos, sumada a los materiales de construcción de los caniles deteriorados o de difícil higiene, se garantiza un nicho propicio para la sobrevivencia de la bacteria. Se definieron como difíciles de asear caniles cuyos materiales de construcción fuesen tierra, ladrillo, madera, combinaciones con estos y con tela, además de carecer de un sistema de desagüe para la eliminación de las excretas por lavado 31,32; por lo tanto, este tipo de criaderos se consideran poco tecnificados. Este tipo de corrales favorecen la exposición de los caninos a la orina, heces y secreciones reproductivas de sus compañeros 31,32 .

Dentro de las prácticas reproductivas que dirige el criador está el servicio reproductivo. En todos los criaderos evaluados, alternan la inseminación artificial con la monta natural, esta última ha sido reportada como una práctica que facilita la transmisión de la bacteria 4,6. Algunos autores sugieren la inseminación artificial, por la protección que brinda al macho de infectarse al realizar servicios reproductivos 36 , sin embargo, para esta también se requiere contar con cuidados como la higiene con los reproductores y los utensilios 
empleados 38. El análisis multivariado definió la higiene deficiente en el servicio reproductivo, tanto por monta natural, como por inseminación artificial, como un factor asociado con la seropositividad canina ( $\mathrm{p}=0,000$; $\mathrm{OR}=64,32$ ), lo cual puede deberse al uso de materiales y utensilios reciclados, así como a inadecuados protocolos de higiene previos y posteriores al servicio reproductivo ${ }^{39}$, tanto con los reproductores, como con la zona donde se lleva a cabo el servicio.

En la mayoría de los criaderos se encontró gran desconocimiento de la enfermedad y poca relevancia a las posibilidades de hacer un diagnóstico oportuno, como la prueba serológica previa al servicio reproductivo; la no realización de esta se determinó como factor asociado por análisis bivariado $(\mathrm{OR}=3,07)$ (Tabla 3). Realizar el diagnóstico serológico para la detección de anticuerpos contra B. canis reduce la probabilidad de tener caninos seropositivos en el criadero, esta práctica viene siendo sugerida 7,38 y aplicada por criadores organizados, que han evitado que sus animales sirvan o sean servidos por otros infectados, principalmente cuando requieren reproductores externos.

A los métodos diagnósticos recurren normalmente sólo después de un evento reproductivo, como aborto o infertilidad, como se ha reportado en diferentes lugares, Hungría 17, Canadá 25 e Italia 40, entre otros. La seropositividad por la prueba PARP-2ME en el criadero, pese a no ser una prueba directa, es un buen indicativo de la circulación de anticuerpos contra B. canis en el criadero 36,40 , por lo tanto, evidencia que en algún momento el perro ha sido bacterémico por la condición ondulante de la infección ${ }^{6}$. El historial de seropositividad en el criadero es un factor asociado con la seropositividad canina actual (Tablas 3 y 4). Los criaderos en los que se presenta esta situación, probablemente han mantenido circulando la bacteria entre sus caninos durante un largo periodo de tiempo, por prácticas reproductivas, convivencia y exposición a fluidos en el ambiente 4 . La decisión de conservar los caninos seropositivos en el criadero (destino de los caninos seropositivos $=$ conservarlos), también constituye un factor asociado (OR $=3,57)$ (Tabla 3), indicando que la permanencia de la condición seropositiva en el criadero se mantiene por las pobres medidas de erradicación de la enfermedad que se aplican.

Los resultados del riesgo de seropositividad para las perras que han presentado al menos un aborto, ratifican la relación entre el principal síntoma de infección en la perra el aborto 36,41 y el resultado serológico positivo, orientando el diagnóstico a brucelosis canina. Se debe resaltar que esta condición subdiagnosticada y sucesiva- mente no controlada, conduce a la circulación de la bacteria.

Con respecto a los humanos convivientes, de ocho criaderos positivos cuatro presentan al menos un conviviente seropositivo. Los humanos positivos en criaderos negativos prestan servicio de inseminación, ginecología y obstetricia a otros criaderos, o son poseedores de más caninos en sus viviendas, los cuales no fueron muestreados en este trabajo. Para estas personas, existe entonces la posibilidad de haber tenido contacto con la bacteria en un lugar diferente a su criadero, realizando una práctica reproductiva o, atendiendo a caninos en etapa de eliminación bacteriana. Aunque la transmisión del género Brucella ocurre animal-animal, o animal-humano 6,16, las personas dedicadas a la realización de prácticas reproductivas, poseedoras de criaderos, deberían tener precauciones con implementos de protección, materiales fungibles y material biológico que pueda representar riesgo a los caninos de su criadero.

Se deben incluir en posteriores análisis otros factores no contemplados en este estudio, como el desempeño u ocupación externa de las personas que conviven en el criadero y la tenencia de caninos. Se debe recordar que la brucelosis se ha catalogado como una enfermedad ocupacional, encontrándose afectados principalmente veterinarios, microbiólogos o laboratoristas y personas expuestas a fluidos reproductivos 42 .

Vale la pena aclarar que los resultados positivos se encontraron en personas relacionadas con criaderos ubicados en la región Valle de Aburrá y de tipo urbano, significando estas dos condiciones factores asociados con la seropositividad humana (OR = 1,20 y 1,19 respectivamente). En estas mismas categorías se encontró la mayor proporción de caninos seropositivos, lo que corresponde al hallazgo en humanos.

La tenencia de caninos infectados ha sido reportada como un riesgo a la salud pública 43,44 , hallándose alrededor de 40 casos de brucelosis canina entre 1966 y 2011 en diferentes lugares del mundo 36 , sin embargo, bajo las condiciones analizadas en este estudio no se estableció la convivencia con caninos seropositivos como un factor de riesgo para las personas.

El contacto humano con la bacteria, representado en el 9\% de seropositividad hallada para ambas regiones, o de un $17 \%$ en la regiónValle de Aburrá, puede ocurrir en los procesos reproductivos de forma accidental, con fluidos en suelos, corrales, utensilios e indumentaria de protección 4,42; y su ingreso a la persona se puede dar por piel lacerada, ingesta oral y mucosas, sea por contacto o aerosoles 45 . La atención segura de los partos, hallada como factor protector para la seronega- 
tividad ( $\mathrm{p}=0,000$; OR $=0,0$ ), refuerza la importancia de la protección personal y la higiene para evitar el contacto de la bacteria con el operario.

Aunque las variables historial de aborto y procedimiento durante un aborto, no representaron factores de riesgo para humanos, sugieren la necesidad de nuevos estudios que permitan determinar el riesgo real de la exposición de personas a fluidos reproductivos, como lo citan Lucero et al. 9. Diferentes autores han descrito la posibilidad e infección humana a partir de fluidos reproductivos caninos, principalmente derivados de parto o aborto, los cuales presentan mayores concentraciones bacterianas, pese a no existir aún una fuerte asociación entre los dos eventos, en Colombia se aisló $B$. canis de un criador, en cuyo criadero se presentaban continuamente trastornos reproductivos y resultados serológicos y microbiológicos positivos a B. canis 11; y en Argentina, el mismo hallazgo se dio en un grupo familiar relacionado con una perra posparto ${ }^{9}$.

Los resultados positivos en humanos alertan a las entidades de salud de países como Argentina, donde empiezan a considerar que esta enfermedad debería estar entre los diagnósticos presuntivos de los médicos, cuando se trata de cuadros febriles e inespecíficos 43. PARP-2ME es la prueba tamiz según Lucero et al. 14,43; sin embargo, se está estudiando la forma de obtener una prueba diagnóstica más sensible para aplicar principalmente en niños, personas inmunodeficientes o mujeres gestantes con cuadros febriles de origen desconocido, esplenomegalia, hepatomegalia y otros signos sistémicos ${ }^{9}$.

Con el fin de seguir de cerca el curso de la enfermedad en caninos, es pertinente sugerir un estudio de tipo longitudinal, con muestreos periódicos a los caninos de núcleos con antecedentes reproductivos o con seropositividad humana, como el caso encontrado en la región Valle de Aburrá; con el fin de descartar fallas en la detección de IgG en caninos en fases iniciales de la enfermedad, dado que PARP-2ME no detecta IgM, y estos caninos formarán parte de los falsos negativos arrojados por la prueba 6,46,47. El estudio longitudinal sería de gran utilidad, además, por la condición de ondulante o insidiosa que poseen en general los diferentes tipos de brucelosis 6,35,40,47,48; es bastante conocido que tanto las bacteremias, como la circulación de anticuerpos contra Brucella sp., ocurren de forma intermitente, existiendo la posibilidad de coincidir los periodos de abacteremia y seronegatividad con el momento del muestreo en estudios tipo transversal como este, tanto en animales como en personas relacionadas. Esta inconveniente coincidencia pudo generar la nulidad en cuanto a la significancia estadística de algunas variables relacionadas con la seropositividad. Es así como algunas variables, que presentaron frecuencia en diferentes criaderos, no alcanzaron un nivel significativo al compararlas con la variable independiente resultado serológico canino. En el caso de los humanos, variables que han sido consideradas de riesgo por otros autores, como atención de abortos de forma insegura y convivencia con caninos seropositivos, pudieron ser afectadas por el tipo de estudio o por la no detección de IgM.

\section{Conclusiones}

La seropositividad a B. canis, tanto en caninos como en humanos convivientes, ha aumentado en los últimos tres años, lo que amerita vigilancia y control epidemiológico.

El aborto, la seropositividad canina, conservar los caninos seropositivos y realizar prácticas reproductivas con deficiente medidas de higiene, son factores asociados con que un criadero esté positivo a B. canis. Asimismo, unos ambientes higiénicos y confortables para los caninos, sumados a prácticas sanitarias y reproductivas adecuadas, favorecen la sanidad en lo que respecta a brucelosis canina.

La tenencia de criaderos en zonas urbanas representa riesgo para la salud humana, se deben realizar más análisis de este tipo para determinar otros factores asociados a la seropositividad.

Se deben realizar estudios de tipo longitudinal con seguimiento serológico, o implementar técnicas directas de alta sensibilidad para diagnosticar la brucelosis canina a nivel de criaderos y personas relacionadas con estos. 


\section{Resumo}

O objetivo desta pesquisa foi determinar a soroprevalência de brucelose dada por Brucella canis na população canina e os seres humanos que moram junto com os cães reprodutores, e explorar os fatores de risco associados à soropositividade. Vinte cães foram amostrados, nestes se fez o diagnóstico sorológico por PARP-2ME para 428 caninos e 91 pessoas. Para o estudo de fatores de risco associados à doença foi realizada uma análise por regressão logística. Encontrou-se uma soroprevalência de $15 \%$ e 9\% nos caninos e humanos, respectivamente. Foram identificados como fatores de risco associados à soropositividade canina nos canis avaliados a história clínica com antigos diagnósticos de abortos e de soropositividade, conservar caninos que sejam soropositivos, a má higiene no canil e uma indumentária laboral insuficiente para o trabalhador que mexe com os cães, tanto durante o serviço reprodutivo quanto na atenção de abortos que possam ser inseguros. Encontraram-se como fatores de proteção nesta pesquisa as regiões rurais onde estava a incubadora, a facilidade de limpeza que possibilita uma melhor higiene dos canis, PARP-2ME pré-nupcial e procedimento seguro durante o parto. Em humanos foram determinados como fatores associados: criadores localizados no Valle Aburrá e do tipo urbano.

Estudos Soroepidemiológicos; Brucelose; Zoonoses

\section{Colaboradores}

L. Castrillón-Salazar, C. A. Giraldo-Echeverri, M. M. Sánchez-Jiménez y M. Olivera-Ángel proporcionaron contribuciones sustanciales a la concepción y el diseño, adquisición de datos o análisis e interpretación de datos, en la redacción del artículo y revisión crítica importante para el contenido intelectual, y aprobaron la versión que será publicada.

\section{Agradecimientos}

A los fondos CODI-Regionalización 2010 y BUPPE 2009 de la Universidad de Antioquia, por la financiación de este proyecto.

\section{Referencias}

1. Skendros P, Pappas G, Boura P. Cell-mediated immunity in human brucellosis. Microbes Infect 2011; 13:134-42.

2. Buzgan T, Karahocagil M, Irmak H, Baran I, Karsen $\mathrm{H}$, Evirgen $\mathrm{O}$, et al. Clinical manifestations and complications in 1028 cases of brucellosis: a retrospective evaluation and review of the literature. Int J Infect Dis 2010; 14:469-78.

3. Carmichael L, Kenney R. Canine abortion caused by Brucella canis. J Am Vet Med Assoc 1968; 152:605-16.

4. Wanke M. Canine brucellosis. Anim Reprod Sci 2004; 82-83:195-207.
5. Briceño H, Páramo RM, Flóres-Castro R, Súarez F. Problemas reproductivos en perros machos infectados con Brucella canis. Vet Méx 2004; 35:121-8.

6. Hollett R. Canine brucellosis: outbreaks and compliance. Theriogenology 2006; 66:575-87.

7. Giraldo C, Ruiz-Cortés Z, Olivera M. Brucella canis en Medellín (Colombia), un problema actual. Revista U.D.C.A. Actualidad \& Divulgación Científica 2009; $12: 210-20$.

8. Ruíz J, Giraldo C, López L, Chica J. Seroprevalencia de Brucella canis en perros callejeros del Centro de Bienestar Animal "La Perla", Medellín (Colombia), 2008. Rev Colomb Cienc Pecu 2010; 23:166-72. 
9. Lucero N, Corazza R, Almuzara M, Reynes E, Escobar G, Boeri E, et al. Human Brucella canis outbreak linked to infection in dogs. Epidemiol Infect 2010; 138:280-5.

10. Pacheco Ríos A. Mascotas en los hogares: enfermedades de los niños adquiridas por convivencia con animales. Enferm Infecc Microbiol 2003; 23:137-48.

11. Olivera M, Di-Lorenzo C. Aislamiento de Brucella canis en un humano conviviente con caninos infectados, reporte de un caso. Colomb Méd 2009; 40:200-15.

12. Baldi PC, Miguel SE, Fossati CA, Wallach JC. Serological follow-up of human brucellosis by measuring IgG antibodies to lipopolysaccharide and cytoplasmic proteins of Brucella species. Clin Infect Dis 1996; 22:446-55.

13. Lucero N, Maldonado P. Brucella canis causing infection in an HIV-infected patient. Vector Borne Zoonotic Dis 2010; 10:527-9.

14. Lucero N, Escobar G, Ayala S, López G. Sensitivity and specificity of an indirect enzyme-linked immunoassay for the diagnosis of Brucella canis infection in dogs. J Med Microbiol 2002; 51:656-60.

15. Megid J, Britto A, Moraes C, Fava N, Agottani J. Epidemiological assessment of canine brucellosis. Arq Bras Med Vet Zootec 1999; 51:94-8.

16. Carmichael L, Green E. Canine brucellosis. In: Greene CE, editor. Infectious diseases of the dog and cat. Philadelphia: WB Saunders Co.; 1990. p. 573-4.

17. Gyuranecz M, Szeredi L, Rónai Z, Dénes B, Dencso L, Dán A, et al. Detection of Brucella canis-induced reproductive diseases in a kennel. J Vet Diagn Invest $2011 ; 23: 143-7$.

18. Stanchi N, Martino P, Gentilino P, Reinoso E, Echeverria N. Microbiología veterinaria. Buenos Aires: Editora Inter-Médica; 2007.

19. Tabbaa D. Control of zoonoses in emergency situations: lessons learned during recent outbreaks (gaps and weaknesses of current zoonoses control programes). Vet Ital 2008; 44:611-20.

20. Carmichael L, Joubert J. A rapid slide agglutination test for the serodiagnosis of Brucella canis infection that employs a variant (M-) organism as antigen. Cornell Vet 1987; 77:3-12.

21. García J. Análisis en los estudios epidemiológicos. VI. Indicadores de riesgo. Madrid: Fundación para el Desarrollo de la Enfermería; 2006. (Nure Investigación, 21).

22. Al-Shamahy H, Whitty C, Wright S. Risk factors for human brucellosis in Yemen: a case control study. Epidemiol Infect 2000; 125:309-13.

23. Delpino MV, Fossati CA, Baldi PC. Proinflammatory response of human osteoblastic cell lines and osteoblast-monocyte interaction upon infection with Brucella spp. Infect Immun 2009; 77:984-95.

24. Wallach JC, Giambartolomei GH, Baldi PC, Fossati CA. Human infection with M- strain of Brucella canis. Emerg Infect Dis 2004; 10:146-8.
25. Brennan SJ, Ngeleka HM, Philibert H, Forbes LB, Allen AL. Canine brucellosis in a Saskatchewan kennel. Can Vet J 2008; 49:703-8.

26. Jara S, Pérez OD, Di-Lorenzo C, Olivera M. Diagnóstico de brucelosis canina mediante aglutinación en placa en caninos de Medellín, Colombia. Rev Colomb Cienc Pecu 2005; 18:4.

27. Castillo V, Cetrino C, Moreno. Encuesta serológica sobre Brucella canis en pacientes atendidos en la clínica de pequeños animales de la Facultad de Medicina Veterinaria y de Zootecnia de la Universidad Nacional de Colombia (Sede Bogotá). Arch Med Vet 2002; 13:22-5.

28. Ramírez H. Prevalencia de brucelosis canina en dos distritos de la Provincia Constitucional del Callao. Rev Investig Vet Perú 2006; 17:39-43.

29. Boeri E, Escobar G, Ayala S, Sosa-Estani S, Lucero N. Brucelosis canina en perros de la ciudad de Buenos Aires. Medicina (B. Aires) 2008; 68:291-7.

30. Pardo A, Pérez C, Góngora A, Gómez L, Moreno A. Encuesta exploratoria de infección por Brucella canis en perros de Villavicencio Colombia. Rev MVZ Córdoba 2009; 14:1690-6.

31. Asure Quality. Pet boarding establishments: code of practice for boarding kennels. Wellington: Asure Quality; 2010.

32. Cline J. Kennel management and nutrition of the bitch and her offspring. In: Lopate C, editor. Management of pregnant and neonatal dogs, cats, and exotic pets. Ames: John Wiley \& Sons; 2012. p.1-13.

33. Álvarez I, Casco M. Determinación de brucelosis en la población canina en ocho barrios del Distrito II de Managua utilizando el método de Rosa de Bengala y rivanol en septiembre-diciembre 2007 [Tesis de Doctorado]. Managua: Universidad Nacional Agraria; 2009.

34. Borie C, Cepeda R, Villarroel M, De los Reyes M. Descripción de características reproductivas en tres perros seropositivos a Brucella canis. Arch Med Vet 2002; 34:17-24.

35. Carmichael L, Joubert J. Transmission of Brucella canis by contact exposure. Cornell Vet 1988; 78: 63-73.

36. Makloski C. Canine brucellosis management. Vet Clin North Am Small Anim Pract 2011; 41:1209-19.

37. Horst S. Sanidad en los trópicos. Buenos Aires: Hemisferio Sur Editorial; 1998.

38. Rezende M. Manejo del apareamiento en la especie canina. In: Gobello C, Olivera M, editoras. El libro latinoamericano de reproducción canina y felina. 2a Ed. Medellín: Fondo Editorial Biogénesis; 2005. p. 201-10.

39. Jiménez C. Inseminación artificial en caninos. In Gobello C, Olivera M, editoras. El libro latinoamericano de reproducción canina y felina. 2a Ed. Medellín: Fondo Editorial Biogénesis; 2005. p. 137-55.

40. Corrente M, Franchini D, Decaro N, Greco G, D'Abramo M, Greco M, et al. Detection of Brucella canis in a dog in Italy. New Microbiol 2010; 33: 337-41. 
41. Akhtardanesh B, Ghanbarpour R, Babaei H, Nazeri M. Serological evidence of canine brucelosis as new emerging disease in Iran. Asian Pacific Journal of Tropical Disease 2011; 1:177-80.

42. Rahman A, Dirk B, Fretin D, Saegerman M, Ahmed U, Muhammad N, et al. Seroprevalence and risk factors for brucellosis in a high-risk group of individuals in Bangladesh. Foodborne Pathog Dis 2012; 9:190-7.

43. Lucero N, Jacob N, Ayala S, Escobar G, Tuccillo P, Jacques I. Unusual clinical presentation of brucellosis caused by Brucella canis. J Med Microbiol 2005; 54:505-8.

44. López G, Ayala S, Efron A, Gómez C, Lucero N. A serological and bacteriological survey of dogs to detect Brucella infection in Lomas de Zamora, Buenos Aires province. Rev Argent Microbiol 2009; 41:97-101.

45. Fugier E, Pappas G, Gorvel JP. Virulence factors in brucellosis: implications for aetiopathogenesis and treatment. Expert Rev Mol Med 2007; 9:1-10.
46. Keid LB, Soares RM, Vasconcellos SA, Megid J, Salgado VR, Richtzenhain LJ. Comparison of agar gel immunodiffusion test, rapid slide agglutination test, microbiological cultura and PCR for the diagnosis of canine brucellosis. Res Vet Sci 2009; 86:22-6.

47. Del Águila J. Detección de anticuerpos contra Brucella canis en 5 criaderos caninos del Departamento de Guatemala por medio de la Prueba Rápida de Aglutinación en Placa 2 $\beta$-Mercaptoetanol (PARPMe) [Tesis de Pregrado]. Ciudad de Guatemala: Universidad de San Carlos de Guatemala; 2007.

48. Marley MS, Rynders PE. Theriogenology question of the month. The infected bitch should be euthanized. The other dogs in the kennel should be quarantined. J Am Vet Med Assoc 2007; 231:867-9.

Recibido el 07/Sep/2012

Versión final presentada el 17/Abr/2013

Aprobado el 03/May/2013 